\title{
THE STUDY OF FOETOMATERNAL OUTCOME IN POST CAESAREAN PREGNANCY IN MKCG MEDICAL COLLEGE, BERHAMPUR, ODISHA
}

\author{
Anee Verma ${ }^{1}$, Subhesh Kumar Bhol'2, Bharati Misra ${ }^{3}$ \\ ${ }_{1}^{1}$ Resident, Department of Obstetrics and Gynaecology, MKCG Medical College, Berhampur. \\ ${ }^{2}$ Resident, Department of Obstetrics and Gynaecology, MKCG Medical College, Berhampur. \\ 3Professor, Department of Obstetrics and Gynaecology, MKCG Medical College, Berhampur.
}

\section{BACKGROUND}

ABSTRACT

Caesarean section has become a procedure of choice in high-risk situations to prevent perinatal morbidity and mortality. But repeat caesarean deliveries performed largely to benefit neonate often result in significant maternal morbidity and mortality.

\section{MATERIALS AND METHODS}

Present study was carried in the Department of Obstetrics and Gynaecology of MKCG Medical College, Berhampur, where 270 cases of post-caesarean pregnancies from June 2015 to May 2016 were studied. History was taken about previous section whether trial was given prior to operation or not. Detailed general examinations were done. Abdominal and Pelvic examinations were done. Relevant investigations were done. Patients were allowed to undergo spontaneous labour and monitored. Emergency repeat CS was done when indicated. Prophylactic low forceps and ventouse application was also done. Condition of baby and mother was noted.

\section{RESULTS}

In our study, repeat CS rate was $82.23 \%$ and VBAC rate was $17.77 \%$. No TOL was given in $71.49 \%$ cases, while in those given successful VBAC rate was $62.3 \%$. Elective CS was done in $14.07 \%$ cases and emergency CS was done in $57.4 \%$ cases. Repeat section after TOL was done in $10.74 \%$ cases. Among the indications of previous CS, CPD (37.03\%) was the leading cause. In repeat CS after TOL leading cause was due to foetal distress (34.48\%) cases as well as same figures in emergency CS. Most common third stage complication and intraoperative finding in RCS was adhesion, while in VBAC it was PPH. There was one neonatal death in VBAC, but none in repeat $\mathrm{CS}$.

\section{CONCLUSION}

In our setting repeat CS rate is very high, as well very few patients have undergone TOL. To improve the maternal morbidity, attempts for successful VBAC should be done. This can be possible only if optimum resources for maternal and foetal monitoring are provided.

\section{KEYWORDS}

VBAC, RCS, TOL, PPH.

HOW TO CITE THIS ARTICLE: Verma A, Bhol SK, Misra B. The study of foetomaternal outcome in post caesarean pregnancy in MKCG Medical College, Berhampur, Odisha. J. Evolution Med. Dent. Sci. 2017;6(89):6241-6245, DOI: 10.14260/jemds/2017/1357

\section{BACKGROUND}

Caesarean birth has been a major source of interest and concern over the last few decades. In the past 35 years, the rate of caesarean section has steadily increased from $5 \%$ to approximately $25 \% .{ }^{[1]}$

Caesarean section, an operation mainly evolved to save a maternal life during difficult childbirth, has now become increasingly the procedure of choice in high-risk situations to prevent perinatal morbidity and mortality. So pregnancy with history of previous caesarean section is prevalent in present day obstetric practice. Cragin's dictum of "once a caesarean always a caesarean" contributed to a $30 \%-50 \%$ rise in caesarean rates in the United States, until it was later replaced by the dictum "once a caesarean trial of labour after selection." [2]

'Financial or Other Competing Interest': None.

Submission 27-09-2017, Peer Review 31-10-2017,

Acceptance 07-11-2017, Published 13-11-2017.

Corresponding Author:

Dr. Anee Verma,

Subham Niwas,

Basudev Nagar, $2^{\text {nd }}$ Lane,

Berhampur, Ganjam-760010.

E-mail:aneemyszu@gmail.com

DOI: $10.14260 / \mathrm{jemds} / 2017 / 1357$
In these studies in which the proportion of women who undertook a planned vaginal birth after previous caesarean varied from $20 \%$ to $80 \%$, successful vaginal birth occurred in $67 \%$ to $84 \%$, averaging about $80 \%$ of the women who made the attempt.[3,4]

In a retrospective study, Cynthia Chazotte et al showed that $2.4 \%$ of the patients after one or more caesarean sections had an extremely serious complication like uterine rupture and placenta previa or accreta with accompanying haemorrhage.[5] Other complications like impending rupture, bladder discomfort and injury, preterm delivery, operative interference and incidental morbidity can occur during pregnancy, labour and in repeat caesarean section.[6]

This prospective study was so designed to find out the maternal antepartum and intrapartum complications as well as perinatal mortality and morbidity in patients with history of previous caesarean section. So, trial of labour in cases of previous caesarean section has been accepted as a way to reduce the overall caesarean rates. A large meta-analysis showed maternal mortality of 2.8 per 10000 for women undergoing planned VBAC and 2.4 per 10000 for women having an elective caesarean. Uterine dehiscence or ruptures occur in less than $2 \%$ of planned VBAC, the same proportion as is seen among women who have routine repeat 
Caesareans. Most of these are asymptomatic and of no clinical importance.

Perinatal mortality and morbidity rates were similar with planned vaginal birth after caesarean and elective repeat caesarean section in these studies.[7] The most important event because of which obstetricians still hesitate to attempt planned VBAC is the uterine scar integrity and hence the terminology "Trial of scar." Because repeat caesarean deliveries are performed largely to benefit the neonate, clinicians may often overlook maternal complications resulting in significant morbidity and mortality as a result of the repeat surgeries.[8] The choice of VBAC over planned repeat caesarean section like virtually every other medical choice involves the balancing of risks and benefits. One point is clear though, "once a caesarean always a hospital delivery."[9] The purpose of this study was to evaluate the obstetric and foetal outcome of labour in cases of previous caesarean section in our teaching hospital. Vaginal birth after caesarean (VBAC) or trial of scar (TOS) represents a significant change in modern obstetric practice. However, the concern that a scarred uterus might end up in rupturing the uterus leading to severe maternal and perinatal morbidity still prevents a large number of obstetricians and pregnant women worldwide from adopting a TOS after previous one caesarean section. Both attempting a vaginal birth and opting for an elective repeat caesarean section (ERCS) are associated with different risks for the mother and the newborn and deciding a delivery plan involves a difficult weighing of those cases.[10] The ability to predict the outcome of an attempted trial of vaginal delivery plays an important role in initial counselling of pregnant women with previous one caesarean delivery.

\section{Aims and Objective}

- To find out any antepartum maternal complication related to previous caesarean section.

- To find out intrapartum maternal and foetal complication.

- To find out the incidence of operative interference in the patients.

- To find out foetal outcome like prematurity, perinatal mortality and morbidity.

\section{MATERIALS AND METHODS}

The present study titled "the study of foetomaternal outcome in post-caesarean pregnancy; a prospective observational study" was carried out in the Department of Obstetrics and Gynaecology of MKCG Medical College, Berhampur. This study includes 270 cases of post-caesarean pregnancies, who had been admitted to this department from June 2015 to May 2016.

A detailed history of patients with special attention to past obstetric history was taken. Emphasis was given to number, indication, type, place, time and postoperative period of previous section, whether trial was given prior to operation or not. Number of vaginal delivery before or after CS was there or not, condition, sex, weight of baby whether alive or dead, if dead cause of death was ascertained.

A detailed history of present pregnancy is taken with emphasis on any complication in earlier trimester. If cases were registered in early trimester, then they were followed up to term and delivery.

Detailed general examination of these patients were done including height and weight. Abdominal examination was done to find out the gestational age of the foetus. Condition of the scar was as a clue to the type of previous section and its post-op period. Height of fundus, abdominal girth, presentation, position, engagement and foetal heart rate were noted carefully. Scar was palpated to elicit scar tenderness.

Pelvis was assessed clinically and possible presence of CPD was also recorded. Presenting part of the foetus and state of the cervix were noted.

Based on history, general examination and pelvic examination patients were selected carefully to undergo TOL, where there was no other contraindication for vaginal delivery. Patients with history of previous two CS, marked contracted pelvis and abnormal presentation were not allowed for TOL. Relevant routine investigations were done in all cases. Most of the patients were allowed to undergo spontaneous labour. The progress of labour was monitored carefully using partograph, scar integrity was tested clinically, early detection of abnormal labour, scar dehiscence, maternal and foetal distress was done.

Emergency repeat CS was done when indicated. Prophylactic low forceps and ventouse application was done in $2^{\text {nd }}$ stage of labour; $3^{\text {rd }}$ stage of labour was managed actively and complication treated. Following delivery of the baby and placenta, uterus was explored to note the condition of the old uterine scar.

Condition of the baby such as living or dead, birth weight, Apgar score, sex and congenital anomaly were noted followed by any morbidity or mortality noted during hospital stay.

Maternal morbidity like PPH, fever, sepsis and mortality were recorded both in vaginal and repeat CS. During repeat CS adhesion, condition of scar, injury to viscera, placental situation and morbid adhesions were recorded.

\section{RESULTS}

Table 1 shows that in our study group, maximum (43.3\%) patients were in 21 - 25 years' age group, were primipara (81.4\%) and interpregnancy interval was 3 - 5 years.

\begin{tabular}{|c|c|c|c|c|c|}
\hline $\begin{array}{c}\text { Age } \\
\text { (years) }\end{array}$ & Value & Parity & Value & $\begin{array}{c}\text { Interval } \\
\text { between } \\
\text { Last and } \\
\text { Current } \\
\text { Pregnancy }\end{array}$ & Value \\
\hline $15-20$ yrs. & $3(1.11 \%)$ & P1 & $\begin{array}{c}220 \\
(81.48 \%)\end{array}$ & $1-2$ years & $\begin{array}{c}33 \\
(12.22 \%)\end{array}$ \\
\hline $21-25$ yrs. & $\begin{array}{c}117 \\
(43.33 \%)\end{array}$ & P2 & $\begin{array}{c}41 \\
(15.18 \%)\end{array}$ & 2-3 yrs. & $\begin{array}{c}64 \\
(23.70)\end{array}$ \\
\hline $26-30$ yrs. & $\begin{array}{c}110 \\
(40.74 \%)\end{array}$ & P3 & $\begin{array}{c}7 \\
(2.59 \%)\end{array}$ & 3-5 yrs. & $\begin{array}{c}126 \\
(46.66 \%)\end{array}$ \\
\hline $31-35$ yrs. & $\begin{array}{c}35 \\
(12.96 \%)\end{array}$ & P4 & $\begin{array}{c}2 \\
(0.74 \%) \\
\end{array}$ & $>5$ yrs. & $\begin{array}{c}47 \\
(17.40 \%) \\
\end{array}$ \\
\hline$>36$ yrs. & $5(1.85 \%)$ & $>\mathrm{P} 4$ & $\begin{array}{c}0 \\
(0 \%)\end{array}$ & Total & $\begin{array}{c}270 \\
(100 \%)\end{array}$ \\
\hline Total & $\begin{array}{c}270 \\
(100 \%)\end{array}$ & Total & $\begin{array}{c}270 \\
(100 \%)\end{array}$ & & \\
\hline \multicolumn{6}{|c|}{$\begin{array}{l}\text { Table 1. Age, Parity Distribution and Interval between } \\
\text { Last and Current Pregnancy }\end{array}$} \\
\hline
\end{tabular}


Graph 1, given below depicts that $71.1 \%$ had no complication antenatally with most common $(15.18 \%)$ being $\mathrm{PIH}$ and least common being GDM and CHD.

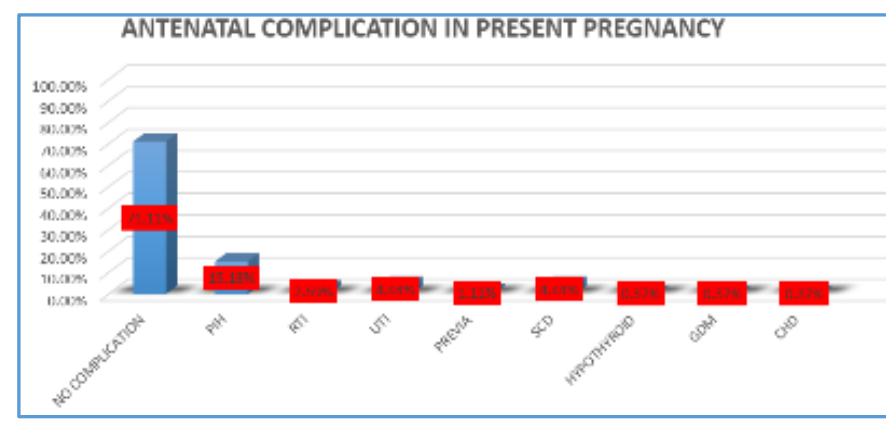

Graph 1. Showing Distribution of Antenatal Complication in Present Pregnancy

\begin{tabular}{|c|c|c|}
\hline Group of Cases & No. of Cases & Percentage \\
\hline $\begin{array}{c}\text { Elective repeat } \\
\text { caesarean section }\end{array}$ & 38 & $14.07 \%$ \\
\hline $\begin{array}{l}\text { Emergency repeat } \\
\text { caesarean section }\end{array}$ & 155 & $57.40 \%$ \\
\hline Selected for TOL & 77 & $28.51 \%$ \\
\hline Successful VBAC & 48 & $17.77 \%$ \\
\hline $\begin{array}{l}\text { Repeat section } \\
\text { after TOL }\end{array}$ & 29 & $10.74 \%$ \\
\hline Total & 270 & $100 \%$ \\
\hline \multicolumn{3}{|c|}{$\begin{array}{c}\text { Table 2. Shows that in Our Study TOL was done in } 28.51 \% \\
\text { Cases with Successful VBAC in } 17.77 \% \text { of Cases }\end{array}$} \\
\hline
\end{tabular}

Table 2, Selection of patients and their mode of delivery.

Graph 2, shows maximum no. of patients (51.85\%) belonged to 38 - 40 weeks gestation with successful VBAC in $8.8 \%$ cases and least no. of patients (5.18\%) were in 28 - 32 weeks' age group with successful VBAC in $2.59 \%$.

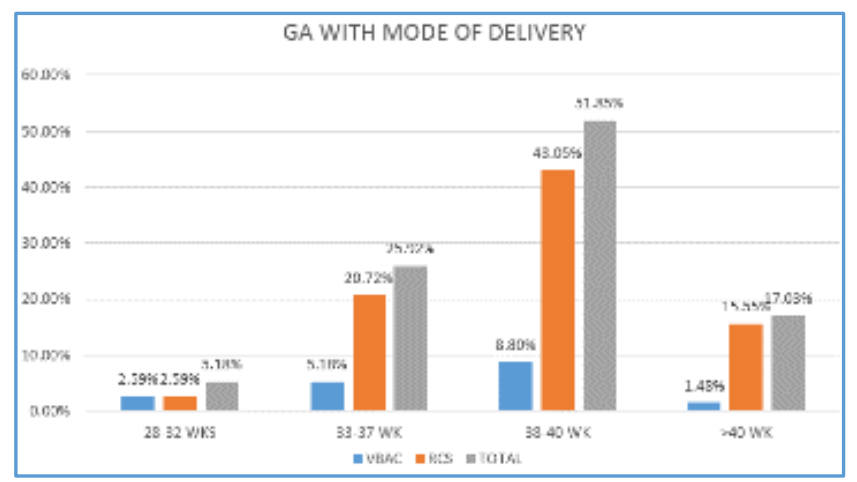

Graph 2. Showing GA with Mode of Delivery

Graph 3 shows that maximum number of patients gone for repeat caesarean section belonged to cephalopelvic disproportion, while maximum number of cases with successful VBAC belonged to foetal distress.

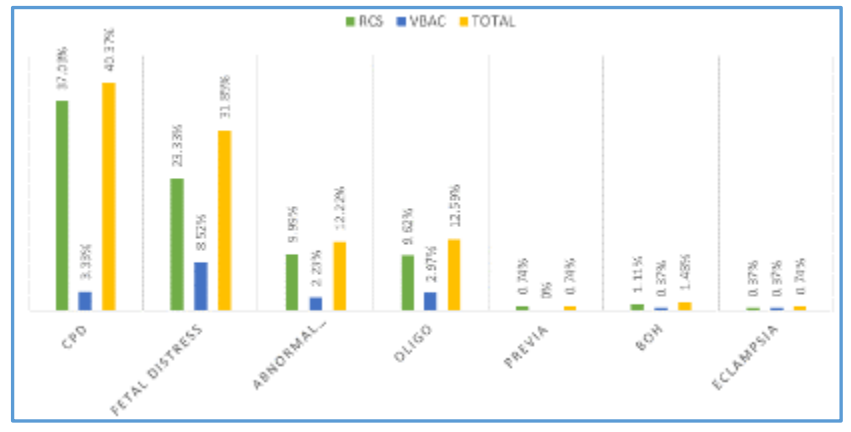

Graph 3. Showing Indication of Previous CS

Table 3 shows foetal distress was the main indication for repeat caesarean in failed TOL. Total number of cases undergoing trial of labour were 29.

\begin{tabular}{|c|c|c|}
\hline Indication & \begin{tabular}{|l|} 
No. of Cases \\
Needed RCS \\
\end{tabular} & Percentage \\
\hline Foetal distress & 10 & $34.48 \%$ \\
\hline Scar tenderness & 9 & $31.03 \%$ \\
\hline Impending rupture & 4 & $13.79 \%$ \\
\hline CPD & 6 & $20.68 \%$ \\
\hline Total & 29 & $100 \%$ \\
\hline
\end{tabular}

Table 4 shows more complications were seen in repeat caesarean groups (48) than VBAC groups (4) with main complication in RCS groups being diffuse intraoperative adhesion and PPH in VBAC patients.

\begin{tabular}{|c|c|c|}
\hline $\begin{array}{l}\text { Complication and } \\
\text { Finding }\end{array}$ & RCS & VBAC \\
\hline PPH & $5(2.25 \%)$ & $2(4.1 \%)$ \\
\hline Adhesion & $22(9.90 \%)$ & \\
\hline Bladder injury & $1(0.45 \%)$ & \\
\hline Cong. anomaly & $6(2.70 \%)$ & $1(2 \%)$ \\
\hline Retained placenta & & $1(2 \%)$ \\
\hline Placenta accreta & $2(0.9 \%)$ & \\
\hline Scar rupture & $8(3.6 \%)$ & \\
\hline $\begin{array}{c}\text { Caesarean } \\
\text { hysterectomy }\end{array}$ & $4(1.8 \%)$ & \\
\hline Total & $48(21.66 \%)$ & $4(8.33 \%)$ \\
\hline
\end{tabular}

Table 5 shows that RCS cases had more postop complication than VBAC cases. Maximum RCS cases suffered from fever and UTI mainly.

\begin{tabular}{|c|c|c|}
\hline Complications & RCS & VBAC \\
\hline Fever & $24(10.81)$ & $2(4.16 \%)$ \\
\hline Wound infection & $8(3.61)$ & 0 \\
\hline $\begin{array}{c}\text { Abdominal } \\
\text { distension }\end{array}$ & $2(0.9 \%)$ & 0 \\
\hline UTI & $15(6.75 \%)$ & $1(2 \%)$ \\
\hline UVF & $1(0.45 \%)$ & 0 \\
\hline Death & $1(0.45 \%)$ & 0 \\
\hline Total & $51(22.97 \%)$ & $3(6.16 \%)$ \\
\hline \multicolumn{3}{|c|}{ Table 5. Shows Postop Complications } \\
\hline
\end{tabular}


Graph 4 shows as the foetal weight increase, the probability of repeat caesarean increase with weight $\geq 4 \mathrm{~kg}$, almost $100 \%$ repeat caesarean section.

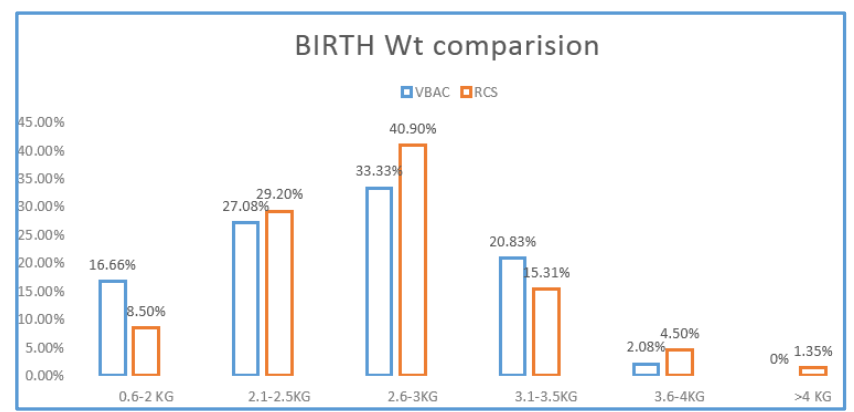

\section{Graph 4. Shows Birth Wt. Comparison between VBAC and RCS}

Table 6 shows out of 48 VBAC, 38 babies were normal and 10 babies suffered complication with asphyxia, still birth, IUGR being most common. While in RCS out of 270, 173 were normal, while 38 suffered complication out of which 11 were still birth.

\begin{tabular}{|c|c|c|c|}
\hline $\begin{array}{c}\text { Condition of } \\
\text { Baby }\end{array}$ & VBAC & RCS & Total \\
\hline Normal & $38(14.07 \%)$ & $173(64.07 \%)$ & $211(78.14 \%)$ \\
\hline Asphyxia & $3(1.11 \%)$ & $13(4.81 \%)$ & $16(5.92 \%)$ \\
\hline IUGR & $2(.74 \%)$ & $14(5.18 \%)$ & $16(5.92 \%)$ \\
\hline Still birth & $3(1.11 \%)$ & $11(4.07 \%)$ & $14(5.18 \%)$ \\
\hline Jaundice & $1(.37 \%)$ & $8(2.96 \%)$ & $9(3.33 \%)$ \\
\hline Infection & 0 & $2(.74 \%)$ & $2(.74 \%)$ \\
\hline Cong. anomaly & 0 & $1(.37 \%)$ & $1(.37 \%)$ \\
\hline Neonatal death & $1(.37 \%)$ & 0 & $1(.37 \%)$ \\
\hline Total & $48(17.77 \%)$ & $222(82.22 \%)$ & $270(100 \%)$ \\
\hline Table 6. Shows Perinatal Outcome in VBAC and RCS \\
\hline \multicolumn{4}{|c}{}
\end{tabular}

\section{DISCUSSION}

With increase of primary CS, there has been a concomitant rise in post caesarean pregnancies. These cases comprise a high-risk group for obstetric care.

The dictum "once a caesarean always a caesarean" was reframed later and suggestions were made that VBAC might reduce rates of CS. Literature showed that the success rate of a TOL after previous CS ranges between $50 \%$ and $85 \%$. In our study, repeat CS rate is $82.23 \%$ and VBAC rate is $17.77 \%$.

TOL given in our study is only in $28.51 \%$ cases, which is very low compared to other studies below.

\begin{tabular}{|c|c|}
\hline Authors & Trial of Labour \\
\hline Singh UK et al (2004) $^{11}$ & $51.3 \%$ \\
\hline Obara et al (1998) $^{12,13}$ & $69.0 \%$ \\
\hline Flamm et al (1994) $^{14}$ & $69.4 \%$ \\
\hline McMahon et al (1996) $^{15,16}$ & $52.9 \%$ \\
\hline Shah et al (2009) $^{17}$ & $51.2 \%$ \\
\hline
\end{tabular}

In our study, successful VBAC rate among TOL is $62.3 \%$ which is comparable to other studies.

\begin{tabular}{|c|c|}
\hline Authors & Success Rate of TOL \\
\hline Singh UK et al (2004) $)^{11}$ & $65.3 \%$ \\
\hline Eriksen et al (1989) & $81.0 \%$ \\
\hline Flamm et al (1994) & $75.0 \%$ \\
\hline Shah et al (2009) 17 & $72.1 \%$ \\
\hline
\end{tabular}

No TOL given in $71.49 \%$ cases, which are very high compared to $49.7 \%$.

Maximum no. of cases belonged to 21 - 25 age group $(43.33 \%)$ followed by 26 - 30 age group (40.74\%), which was low compared to study by Shah et al 2009 which showed $63.5 \%$ cases belonged to age group 26 - 30.17 Para one constitutes $81.48 \%$ cases, which correlates well with study by SN Goswami et al. ${ }^{19}$ Indication for previous CS is the most important factor in deciding the mode of delivery in subsequent pregnancies. The indications are foetal distress in $23.33 \%$ cases, which is comparable to $21.8 \%$ cases as seen in study by Shah et al. ${ }^{17}$ Indications of CPD was seen in $37.03 \%$ cases as compared to $42.2 \%$ cases in the above study by Shah et al. ${ }^{17}$ Abnormal presentation was seen in $9.9 \%$ cases as compared to $13.3 \%$ cases in study by Shah et al.17,20 Oligohydramnios are seen in $9.62 \%$ cases as compared to $1 \%$ seen by Jha $M$ et al. ${ }^{20}$ Eclampsia are seen in $37 \%$ cases as comparable to $1 \%$ as study by Jha $\mathrm{M}$ et al. ${ }^{20}$ Previa occurred in $0.74 \%$ cases, which is less compared to $5.6 \%$ as study by Shah et al. ${ }^{17} \mathrm{BOH}$ was seen in $1.11 \%$ cases as compared to $2 \%$ as study by Jha $\mathrm{M}$ et al. ${ }^{20}$ Non-recurrent indications of previous CS are given TOL. All the indications of RCS in failed TOL are foetal distress in $34.48 \%$ cases, scar tenderness seen in $31.03 \%$ cases, CPD seen in $20.68 \%$ cases and impending rupture in $13.79 \%$.

\section{During Antenatal Period}

No complications are seen in $71.11 \%$ cases. However, among the complications, PIH are seen in $15.18 \%$ cases, UTI are seen in $4.44 \%$ cases, SCD are seen in $4.44 \%$ cases, RTI are seen in $2.59 \%$ cases and placenta previa are seen in $1.11 \%$ cases Hypothyroidism, GDM and CHD are also seen in $0.37 \%$ each.

\section{Complications are seen in 3rd Stage of Labour and} Interoperation Stage

Among RCS, complications are seen in $21.66 \%$ cases. Out of which extensive adhesions are seen in $9.90 \%$ cases, scar rupture in $3.6 \%$ cases, cong. anomaly of uterus in $2.7 \%$ cases, $\mathrm{PPH}$ in $2.25 \%$ cases, caesarean hysterectomy in $1.8 \%$ cases, placenta accreta in $0.9 \%$ cases and bladder injury in $0.45 \%$ cases.

Among VBAC cases, complications occurred in $8.33 \%$ cases. Out of which, PPH are seen in $4.1 \%$ cases, retained placenta in $2 \%$ cases and cong. anomaly of uterus in $2 \%$ cases. Post-operative complications are also seen.

Among the RCS cases, complications are seen in $22.97 \%$ cases. Out of which, pyrexia in $10.81 \%$ cases, UTI in $6.75 \%$ cases, wound infection in $3.6 \%$ cases, abdominal distension in $0.9 \%$ cases, UVF in $0.45 \%$ cases and maternal mortality are seen in $0.45 \%$ cases.

Among VBAC cases, complications are seen in 6.16\% cases. Out of which, pyrexia in $4.16 \%$ cases and UTI seen in $2 \%$ cases.

Birth weight of babies between $2.6-3.0 \mathrm{~kg}$ are seen in $39.62 \%$ cases, between $2.1-2.5 \mathrm{~kg}$ are seen in $28.88 \%$ cases and $3.1-3.5 \mathrm{~kg}$ are seen in $16.29 \%$ cases. Our study does not match with one study, in which $36.3 \%$ cases babies belonged to $3.5-4 \mathrm{~kg}, 30.8 \%$ of babies belonged to $3-3.5 \mathrm{~kg}$ and $16.1 \%$ of babies had birth wt. $>4 \mathrm{~kg}$.

Perinatal outcome are normal in $78.14 \%$ cases. Birth asphyxia are seen in $5.92 \%$ cases, out of which $4.81 \%$ cases 
are seen in RCS and $1.11 \%$ are seen in VBAC. IUGR are seen in $5.92 \%$ cases, out of which $5.18 \%$ cases are seen in RCS and $0.74 \%$ are seen in VBAC. Stillborn are seen in $5.18 \%$ cases, out of which $4.07 \%$ cases are seen in RCS and $1.11 \%$ cases are seen in VBAC.

\section{CONCLUSION}

Caesarean section, an operation mainly evolved to save a maternal life during difficult childbirth has now become increasingly the procedure of choice in high-risk situations to prevent perinatal morbidity and mortality. So pregnancy with history of previous caesarean section is prevalent in present day obstetric practice. Cragin's dictum of "Once a caesarean always a caesarean" contributed to a $30 \%-50 \%$ rise in caesarean rates in the United States until it was later replaced by the dictum "Once a caesarean trial of labour after selection" of patient had an extremely serious complication like uterine rupture and placenta previa or accreta with accompanying haemorrhage. Other complications like impending rupture, bladder discomfort and injury, preterm delivery, operative interference and incidental morbidity can occur during pregnancy and labour in repeat caesarean section. TOL in previous caesarean section has been accepted to reduce the overall caesarean rates. The most important event because of which obstetricians still hesitate to attempt planned VBAC is uterine scar integrity and hence terminology "trial of scar" has evolved. Because repeat caesarean deliveries are performed largely to benefit neonate, clinicians often overlook maternal complications resulting in significant morbidity and mortality as a result of the repeat surgeries. One point is clear though, "once a caesarean always a hospital delivery." Vaginal birth after caesarean (VBAC) or trial of scar (TOS) represents a significant change in modern obstetric practice. Thus, the ability to predict outcome of an attempted VBAC plays an important role in reducing morbidity and mortality with pregnant women with previous one caesarean delivery.

\section{REFERENCES}

[1] Marc H. Incerpi, MD, Operative Delivery in Alan H, Decherney, MD, Current diagnosis \& treatment obstetrics \& gynecology. 10 $10^{\text {th }}$ edn. McGraw-Hill Companies, USA, 2007:461-76.

[2] Cragin EB. Conservatism in obstetrics. NY Med J 1916;104(1916):1-3.

[3] Menacker F, Curtin SC. Trends in caesarean birth and vaginal birth after previous caesarean, 1991-99. Natl Vital Stat Rep 2001;49(13):1-16.

[4] Enkin M, Keirse MJ, Neilson J, et al. Effective care in pregnancy and childbirth: a synopsis. Birth 2001;28(1):41-51.
[5] Chazotte C, Cohen WR. Catastrophic complications of previous caesarean section. Am J Obstet Gynecol 1990;163(3):738-42.

[6] Dutta DC. Pregnancy with history of previous caesarean section. $6^{\text {th }}$ edn. Textbook of obstetrics including perinatology and contraception. 2005;8794:345-6.

[7] Rosen MG, Dickinson JC, Westhoff CL. Vaginal birth after caesarean: a meta-analysis of morbidity and mortality. Obstet Gynecol 1991;77(3):465-70.

[8] Fang YM, Zelop CM. Vaginal birth after caesarean: assessing maternal and perinatal risks-contemporary management. Clin Obstet Gynecol 2006;49(1):147-53.

[9] Jhaveri A. Obstetric career after previous caesarean section. J Obstetric Gynecology India 1969;19:561.

[10] National Institutes of Health Consensus Development Conference Panel. NIH consensus development conference statement: vaginal birth after caesarean: new insights march 8-10, 2010. Obstet Gynecol 2010;115(6):1279-95.

[11] Singh T, Justin CW, Haloob RK. An audit on trends of vaginal delivery after one previous caesarean section. J Obstet Gynaecol 2004;24(2):135-8.

[12] Obara H, Minakami H, Koike T, et al. Vaginal birth after caesarean delivery: results in 310 pregnancies. J Obstet Gynaecol Res 1998;24(2):129-34.

[13] Society of obstetric \& gynecologist of Canada. Vaginal birth after previous caesarean birth. Clin Practical Guideline no 68, Ottawa SOGC, December, 1997.

[14] Flamm BL, Goings JR, Liu Y, et al. Elective repeat cesarean delivery versus trial of labor: a prospective multicenter study. Obstet Gynecol 1994;83(6):927-32.

[15] McMahon MJ, Luther ER, Bowes WA, et al. Comparison of a trial of labour with an elective second caesarean section. N Eng J Med 1996;335(10):689-95.

[16] Chua S, Arullamaran S, Singh P, et al. TOL after prev CS. Obstetric outcome Aust. NZ J Obst Gynecol 1989;29:12-7.

[17] Shah JM, Mehta MN. Analysis of mode delivery in women with previous one caesarean section. J Obstet Gynecol India 2009;59:136-9.

[18] Eriksen NL, Buttino L. Vaginal birth after cesarean: a comparison of maternal and neonatal morbidity to elective repeat cesarean section. Am J Perinatol 1989;6(4):375-9.

[19] RCOG. The sentinel national caesarean section audit report. RCOG clinical effectiveness support unit, RCOG press, 2001.

[20] Jha M. Pregnancy outcome of single previous caesarean section. J Nepal Health Res Counc 2009;7(14):25-8. 